\title{
Genetic parameters of endocrine fertility traits based on in-line milk progesterone profiles in Swedish Red and Holstein dairy cows
}

\author{
G. M. Tarekegn, ${ }^{1,2 *} \odot$ P. Gullstrand, ${ }^{2} \oplus$ E. Strandberg, ${ }^{2} \odot$ R. Båge, ${ }^{3,4} \odot$ E. Rius-Vilarrasa, ${ }^{4}$ J. M. Christensen, ${ }^{5} \oplus$ \\ and $B$. Berglund ${ }^{2 *}$ \\ ${ }^{1}$ Department of Animal Breeding and Genetics, Centre for Reproductive Biology in Uppsala, Swedish University of Agricultural Sciences, \\ PO Box 7023, SE-750 07 Uppsala, Sweden \\ ${ }^{2}$ Department of Animal Production and Technology, Bahir Dar University, PO Box 79, Bahir Dar, Ethiopia \\ ${ }^{3}$ Department of Clinical Sciences, Centre for Reproductive Biology in Uppsala, Swedish University of Agricultural Sciences, PO Box 7054, \\ SE-750 07 Uppsala, Sweden \\ ${ }^{4}$ Växa Sverige, PO Box 30204, SE-104 25 Stockholm, Sweden \\ ${ }^{5}$ Lattec, Slangerupsgade 69, 3400 Hillerod, Denmark
}

\section{ABSTRACT}

Evaluating fertility traits based on endocrine progesterone profiles is becoming a promising option to improve dairy cow fertility. Several studies have been conducted on endocrine fertility traits, mainly in the Holstein breed. In this study, focusing also on the Swedish Red (SR) breed, genetic parameters were estimated for classical and endocrine fertility traits, the latter based on in-line milk progesterone records obtained for 14 Swedish herds using DeLaval Herd Navigator (DeLaval International, Tumba, Sweden). A total of 210,403 observations from 3,437 lactations of 1,107 SR and 1,538 Holstein cows were used. Mixed linear animal models were used for estimation of genetic parameters. Least squares means analysis showed that Holstein cows had a 2.5-d-shorter interval from calving to commencement of luteal activity (C-LA) and longer length of first inter-ovulatory interval (IOI) than SR cows. The highest mean interval for C-LA, IOI, and first luteal phase length (LPL) was observed in the fourth parity. The incidence of short $(<18 \mathrm{~d})$, normal, $(18-24 \mathrm{~d})$, and long (>24 d) IOI was 29.3, 40.7 , and $30 \%$, respectively. Genetic analysis indicated moderate heritability $\left(h^{2}\right)$ for C-LA $\left(h^{2}=0.24\right)$, luteal activity during the first $60 \mathrm{~d}$ in milk (LA60, $\left.h^{2}=0.15\right)$, proportion of samples with luteal activity (PLA, $h^{2}=$ $0.13)$, and calving to first heat $\left(\mathrm{CFH}, h^{2}=0.18\right)$, and low heritability estimates for LPL $\left(h^{2}=0.08\right)$ and IOI

\footnotetext{
Received March 27, 2019.

Accepted August 24, 2019.

*Corresponding authors: yafetgetinet@gmail.com and britt. berglund@slu.se
}

$\left(h^{2}=0.03\right)$ in the combined data set for both breeds. Similar heritability estimates were obtained for each breed separately except for IOI and LPL in SR cows, for which heritability was estimated to be zero. Swedish Red cows had 0.01 to 0.06 higher heritability estimates for C-LA, LA60, and PLA than did Holstein cows. Calving interval had moderate heritability among the classical traits for Holstein and the combined data set, but $h^{2}$ was zero for SR. Commencement of luteal activity had a strong genetic correlation with LA60 (mean $\pm \mathrm{SE} ;-0.88 \pm 0.06)$, PLA $(-0.72 \pm 0.11)$, and $\mathrm{CFH}$ $(0.90 \pm 0.04)$. Similarly, CFH had a strong genetic correlation with IOI $(0.98 \pm 0.20)$. Number of inseminations per series showed a weak genetic correlation with all endocrine traits except IOI. Overall, endocrine traits had higher heritability estimates than classical traits in both breeds, and may have a better potential to explain the actual reproductive status of dairy cows than classical traits. This might favor inclusion of some endocrine fertility traits - especially those related to commencement of luteal activity - as selection criteria and breeding goal traits if recording becomes more common in herds. Further studies on genetic and genomic evaluations for endocrine fertility traits may help to provide firm conclusions. A prerequisite is that the data from automatic devices be made available to recording and breeding organizations in the future and included in a central database.

Key words: correlation, heritability, luteal activity, progesterone

\section{INTRODUCTION}

Dairy cows have suffered a decline in fertility, reflected by an extended anestrous period, less pronounced estrous behavior (Leroy et al., 2008), and increased 
prevalence of atypical progesterone $(\mathbf{P} 4)$ profiles (Royal et al., 2000a; Nyman et al., 2014). Understanding the underlying biology that contributes to low fertility, developing strategies to improve fertility, and utilizing automated tools to reveal cow fertility status remain major challenges in research on dairy cattle (Walsh et al., 2011). Most fertility improvement interventions to date have focused on classical traits based on insemination records. However, these traits are highly influenced by environmental factors and management decisions (Nyman et al., 2014; Tenghe et al., 2015). As an alternative, the use of endocrine traits, based on in-line milk measurements, to improve dairy cow fertility has been suggested. This is because they are less affected by environment and management decisions (Royal et al., 2000b; Nyman et al., 2014) and provide objective and accurate measurements of ovarian activity (Petersson et al., 2006a). Endocrine traits better reflect the physiology and reproductive status of the cow, which often leads to higher heritability estimates compared with classical traits (Friggens and Chagunda, 2005; Martin et al., 2013; Tenghe et al., 2015). Recent studies on endocrine fertility traits show encouraging heritability and genetic correlation estimates and these traits can be useful indicators of fertility to consider in the selection criteria and breeding goal (Nyman et al., 2014; Tenghe et al., 2015; Häggman et al., 2019). Therefore, the aim of this study was to perform a comprehensive evaluation of endocrine fertility traits in the 2 most common breeds in Swedish dairy herds, using progesterone profiles derived from in-line milk progesterone measurements.

In-line milk progesterone profiles are generated by the automated management system Herd Navigator (DeLaval International, Tumba, Sweden), a decision support tool developed for monitoring energy balance, mastitis, and fertility in dairy cows (Friggens and Chagunda, 2005; DeLaval International, 2011). It enables monitoring of fertility status in dairy cows and reduces time-consuming visual heat detection (Saint-Dizier and Chastant-Maillard, 2012; Adriaens et al., 2017). Moreover, it helps to identify the onset and end of luteal phases and to determine estrus and pregnancy status (Adriaens et al., 2018; Häggman et al., 2019). Overall, this tool can enable timely identification of a cow's reproductive status, helping to minimize fertility-related losses on dairy farms (e.g., Adriaens et al., 2018). In recent years, Herd Navigator has been installed on several dairy farms in Sweden. This provides the opportunity to evaluate endocrine fertility traits of Swedish Red cows in a large data set. Apart from a recent study in Finland (Häggman et al., 2019), most progesteronebased fertility studies to date have focused on Holstein cows (Berry et al., 2012; Nyman et al., 2014; Tenghe et al., 2015; Adriaens et al., 2017, 2018; Bruinjé et al., 2019). In this study, we estimated genetic parameters for classical and endocrine traits, the latter based on in-line milk progesterone records, in both Swedish Red and Holstein dairy cows.

\section{MATERIALS AND METHODS}

A total of 14 Swedish dairy herds comprising Swedish Red (SR) and Holstein cows were included in the study. In-line milk P4 samples were automatically collected and analyzed by Herd Navigator. In the initial data set, $83.2 \%$ of the records were the only sample taken on that day; however, some cows had more than one $\mathrm{P} 4$ value for a given day. We used records from October 2015 to October 2017. The endocrine traits studied were interval from calving to commencement of luteal activity (C-LA), length of first inter-ovulatory interval (IOI), length of inter-luteal interval (ILI), first luteal phase length (LPL), luteal activity during the first 60 DIM (LA60; categorical 0 or 1), proportion of samples with luteal activity during the first 60 DIM (PLA; Figure 1), and interval from calving to first heat (CFH) and the occurrence of atypical profiles. The classical traits included calving interval (CInt), interval from calving to first insemination (CFI), interval from calving to last insemination (CLI), interval from first to last insemination (FLI), number of inseminations per series (NINS), and the mixed (endocrine and classical) trait interval from commencement of luteal activity to first service (CLAFS). Endocrine fertility traits were defined from progesterone profile data provided by Lattec I/S (Hillerød, Denmark) and based on a recent report by Tenghe et al. (2015). A progesterone concentration of $5 \mathrm{ng} / \mathrm{mL}$ was used as the threshold to define progesterone profiles. Pedigree, calving, and insemination data used to assess classical fertility traits were obtained from Växa Sverige (Stockholm, Sweden).

Individual progesterone profiles were plotted against DIM using SAS software (ver. 9.2; SAS Institute, 2012; Figure 1). The progesterone profiles were manually classified into normal and atypical (delayed cyclicity: P4 concentrations below the predefined P4 threshold for more than $56 \mathrm{~d}$ postpartum; prolonged luteal phase: high P4 levels $>5 \mathrm{ng} / \mathrm{mL}$ for at least $20 \mathrm{~d}$; cessation of cyclicity: cyclicity interrupted for at least $14 \mathrm{~d}$ with $\mathrm{P} 4$ concentrations below the $\mathrm{P} 4$ threshold value) progesterone profiles. Details of the atypical profile classification were reported by Nyman et al. (2014). The incidence of IOI was classified as short (IOI $<18 \mathrm{~d}$ ), normal $(18 \leq$ IOI $\leq 24 \mathrm{~d}$ ), or long (IOI $>24 \mathrm{~d}$ ) cycle (Nyman et al., 2014). 


\section{Filtering Criteria}

The data were filtered at the herd level and the lactation level. Herd-level filtering criteria were as follows: (1) lactation was retained if interval from calving to start of herd $\mathrm{P} 4$ recording was $\leq 20 \mathrm{~d}$; and (2) lactation was retained if interval from calving to end of herd recording was $\geq 60$ d. Lactation-level filtering criteria were as follows: (1) P4 samples taken before 20 DIM in lactation were excluded; and (2) lactations in which $\mathrm{P} 4$ recording started after 35 DIM were excluded. The numbers of samples, cows, and lactations retained after applying the filtering criteria are shown in Table 1.

For specific traits at the cow lactation level, the following restrictions were applied if the cow's lactation had no P4 records for more than $7 \mathrm{~d}$ : all traits were retained if the gap occurred one or more days before C-LA and the gap duration was less than $15 \mathrm{~d}$, or if the gap occurred more than $24 \mathrm{~d}$ after C-LA. To handle herd-specific gaps, the following restrictions were applied to that herd: all traits were retained if a gap of at least $3 \mathrm{~d}$ occurred one or more days before C-LA. The following restrictions were applied if a gap of 3 or more days occurred after C-LA: (1) LPL was retained if the gap occurred more than $24 \mathrm{~d}$ after C-LA; (2) ILI was retained if the gap occurred at least $1 \mathrm{~d}$ before the start of inter-luteal interval; (3) IOI was retained if the gap occurred at least $1 \mathrm{~d}$ before the start of next luteal cycle. Insemination events that occurred before the start of recorded luteal activity were excluded. For CInt, CLI, and FLI, records above 730, 300, and $300 \mathrm{~d}$, respectively, were excluded.

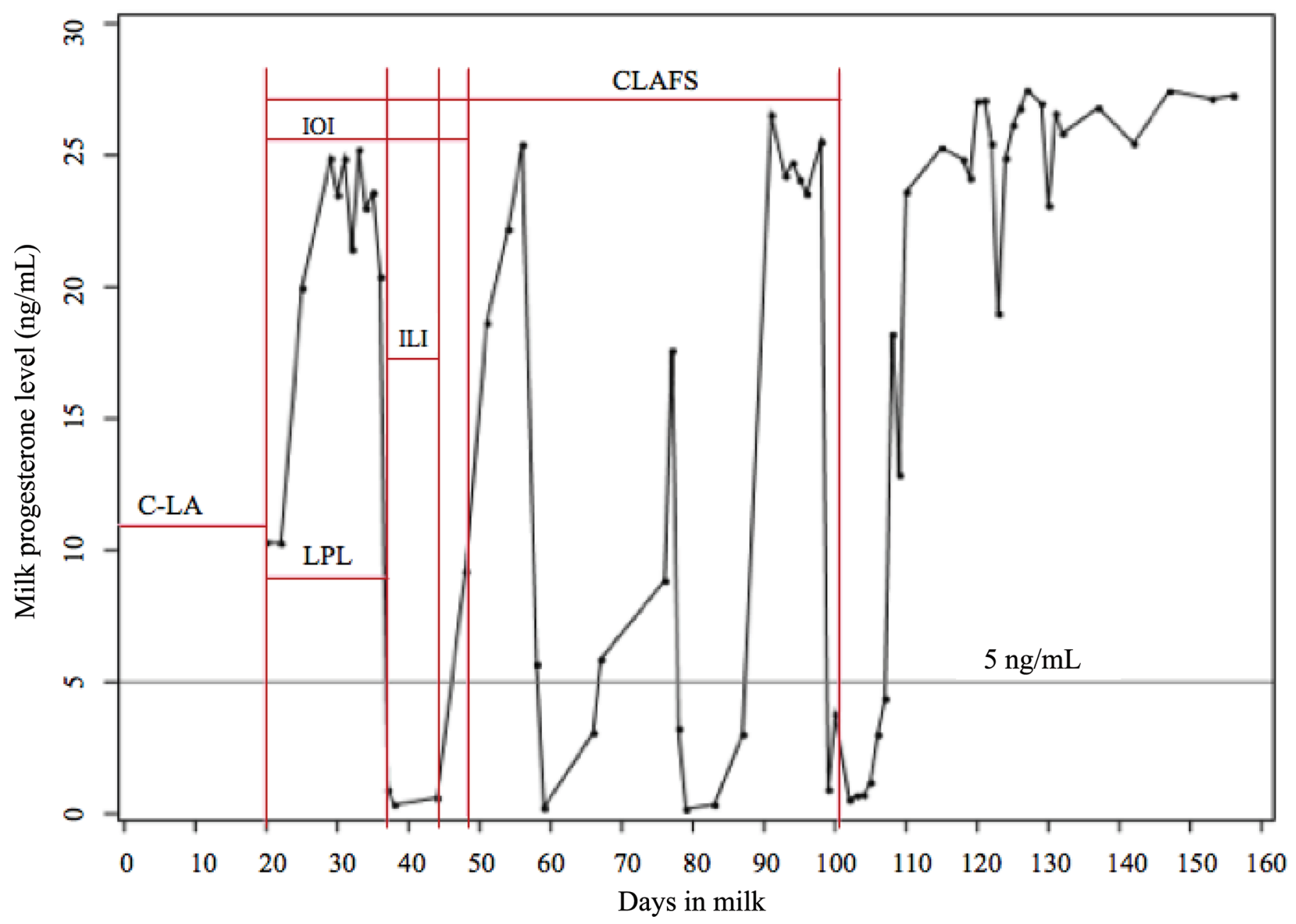

Figure 1. Milk progesterone curve for endocrine fertility traits, generated from a cow used in the study. C-LA = commencement of luteal activity; LPL = first luteal phase length; IOI = length of first inter-ovulatory interval; ILI = length of first inter-luteal interval; CLAFS = interval from commencement of luteal activity to first service. A threshold of $5 \mathrm{ng} / \mathrm{mL}$ was used to determine whether the cow had luteal activity. 
Table 1. Number $(\mathrm{N})$ of progesterone (P4) samples, lactations, and cows retained after applying filtering criteria at the herd and lactation levels

\begin{tabular}{|c|c|c|c|c|c|c|}
\hline \multirow[b]{2}{*}{ Criteria } & \multicolumn{2}{|c|}{ P4 samples } & \multicolumn{2}{|c|}{ Lactation } & \multicolumn{2}{|c|}{ Cows } \\
\hline & $\mathrm{N}$ & $\%$ & $\mathrm{~N}$ & $\%$ & $\mathrm{~N}$ & $\%$ \\
\hline Start data & 286,321 & 100 & 5,371 & 100 & 3,653 & 100 \\
\hline Herd level $^{1}$ & 243,072 & 85 & 4,154 & 77.3 & 3,094 & 84.7 \\
\hline Lactation level $^{2}$ & 210,403 & 73 & 3,437 & 64 & 2,645 & 72.4 \\
\hline
\end{tabular}

${ }^{1}$ Herd-level filtering excluded lactations with interval from calving to start of $\mathrm{P} 4$ recording $>20 \mathrm{~d}$ and lactations with interval from calving to end of $\mathrm{P} 4$ recording $<60 \mathrm{~d}$.

${ }^{2}$ Lactation-level filtering excluded P4 records taken before 20 DIM and lactations with start of P4 recording $>35$ DIM

\section{Statistical Analysis}

Effects of breed, parity, and season on endocrine and classical fertility traits were estimated using a general linear model in SAS software (ver. 9.2; SAS Institute, 2012):

$$
y_{i j k l}=\mu+B_{i}+P_{j}+S_{k}+e_{i j k l},
$$

where $y_{i j k l}$ is the analyzed trait; $\mu$ is the overall mean; $B_{i}$ is the fixed effect of the $i$ th breed (SR or Holstein); $P_{j}$ is the fixed effect of $j$ th parity (lactation) $(j=1, \ldots$, 5 ; parities $>5$ were merged into the fifth parity); $\mathrm{S}_{k}$ is the fixed effect of $k$ th calving season ( $k=$ March-May, June-August, September-November, and DecemberFebruary); and $e_{i j k l}$ is the random error. Because 2 herds had only SH cows, it was not possible to estimate a herd effect free of the breed effect. Therefore, the herd effect was not included. Heritabilities and genetic correlations were estimated using a mixed linear animal model in the DMU package (Madsen and Jensen, 2013). Breed and parity were used as fixed effects in the model for combined analysis of SR and Holstein cows, whereas parity was the only fixed effect used in separate analysis of the breeds. Herd-year-season (hys) combinations and cow were fitted as random effects in the model. Univariate analysis was used for all classical and endocrine fertility traits. Bivariate analysis was used to estimate the correlation between endocrine and classical fertility traits. All traits except LA60, PLA, and NINS were (natural) log-transformed. The model used for both univariate and bivariate analyses of the joint data set of Swedish Red and Holstein cows was

$$
y_{i j k l m}=\mu+B_{i}+P_{j}+h y s_{k}+a_{l}+\mathrm{e}_{i j k l m},
$$

where $y_{i j k l m}$ is the analyzed trait; $\mu, B_{i}$, and $P_{j}$ are as in model [1]; $h y s_{k}=$ is the random effect of herd-yearseason combination $k$ (14 herds, years 2015, 2016, and 2017, and the 4 seasons described in model [1]), $\sim \operatorname{IND}\left(\mathbf{0}, \sigma_{H Y S}^{2}\right)$; where IND is independent, normally distributed, $\sigma_{H Y S}^{2}$ is the random additive herd year sea- son variance, $a_{l}$ is the random additive genetic effect of cow $l$ with $\operatorname{var}(a), \sim N D\left(\mathbf{0}, \mathbf{A} \sigma_{a}^{2}\right)$, where $N D$ is normally distributed, $\sigma_{a}^{2}$ is the additive genetic variance, $\mathbf{A}$ is the additive relationship matrix using pedigree information traced back 5 generations for 33,120 animals; and $\mathrm{e}_{i j k l m}$ is the random residual with $\operatorname{var}(e) \sim \operatorname{IND}\left(\mathbf{0}, \sigma_{e}^{2}\right)$, where $\sigma_{e}^{2}$ is the residual variance. Heritability was estimated as $\hat{\sigma}_{a}^{2} /\left(\hat{\sigma}_{a}^{2}+\hat{\sigma}_{e}^{2}\right)$ and standard error (SE) as in Edwards (2017).

\section{RESULTS}

\section{Descriptive Analysis of Endocrine and Classical Fertility Traits}

The endocrine and classical traits of the herds in the study sample are summarized in Table 2. After applying the filtering criteria, the lowest number of observations remained for ILI $(\mathrm{n}=1,412)$ among the endocrine traits and for CInt $(\mathrm{n}=1,084)$ among the classical traits. The number of observations for atypical profiles was low, particularly because they were generated only from the first estrous cycle. The average values obtained for endocrine traits were higher in Holstein than in SR cows, except for C-LA and CFH. This was also the case for classical traits. The proportion of samples with luteal activity (PLA) was 6 percentage points lower for SR cows than for Holstein cows. The incidence of short, normal, and long IOI was 29.3, 40.7, and 30\%, respectively. From the total of 2,793 P4 profiles generated from 2,283 cows, $70 \%$ of the lactations obtained from $75.1 \%$ of cows (data not shown) had a normal profile, and $19.2 \%$ of the cows had atypical profiles that constituted $16.5 \%(\mathrm{n}=460)$ of the total $\mathrm{P} 4$ profiles. The remaining $13.5 \%$ of the profiles obtained from $5.7 \%$ of the cows were categorized as neither normal nor atypical, and might be explained by early pregnancy. Prolonged luteal phase had an incidence of $12.9 \%$ (from total LPL) and cessation of cyclicity had an incidence of $4.5 \%$ (from total ILI). 
Holstein cows started luteal activity 2.5 d earlier and had a luteal phase $2.4 \mathrm{~d}$ longer and IOI $3.0 \mathrm{~d}$ longer than SR cows (Table 3). Cows in their first parity started luteal activity $4.5 \mathrm{~d}$ earlier than cows in their fourth parity. Similarly, cows in their first parity had first estrus $6.8 \mathrm{~d}$ earlier, LPL $3.5 \mathrm{~d}$ shorter, ILI 2.1 $\mathrm{d}$ shorter, and ovulatory interval $5.3 \mathrm{~d}$ shorter than cows in fourth parity. Calving season had a significant influence on C-LA; the highest estimate was obtained in spring and the lowest in summer (Table 3). Similarly, calving season influenced LA60, PLA, NINS, and CInt. Cows calving during the summer had a C-LA 4 d earlier than cows calving during spring. Similarly, cows calving during summer had an LA60 6 percentage points higher and PLA 4 percentage points higher than spring calvers. However, we observed no association of season $(P>0.05)$ with LPL, ILI, IOI, or LA60. Number of inseminations per series (NINS) was 30 percentage points higher for Holstein than for SR cows and 27 percentage points higher in autumn than in spring.

\section{Heritability Estimates}

Among the endocrine fertility traits, C-LA had the highest estimates of heritability 0.24 to 0.26 , whereas LA60, PLA, and CFH had moderate heritability es- timates for SR, Holstein, and the combined data set (Table 4). The heritabilities for LA60 and PLA in SR cows were 0.20 and 0.14 , respectively, which was higher than the heritability estimated for Holstein $(0.14$ and 0.12 , respectively), albeit not significantly higher. However, unlike in Holstein, zero heritabilities were obtained for IOI, LPL, and ILI among the endocrine fertility traits, for CLAFS, and for the classical fertility traits CFI, CLI, and CInt in SR cows. Prolonged luteal phase and delayed cyclicity had moderate heritability estimates, whereas cessation of cyclicity had zero heritability. Among the classical traits, CInt had moderate heritability (0.15) in the combined data set and in Holstein cows (0.16). The estimated heritability for NINS was 0.02 to 0.06 .

\section{Genetic Correlations}

Due to zero or very low heritability estimates and small sample size, genetic correlation analysis was carried out only for selected traits in the combined data set for both breeds (Table 5). The results revealed that C-LA had strong genetic correlations with $\mathrm{CFH}$ (0.90), LA60 (-0.88), and PLA (-0.72), and CLAFS was strongly correlated with PLA (0.99). Similarly, $\mathrm{CFH}$ had strong genetic correlations with IOI (0.98)

Table 2. Summary statistics [number $(\mathrm{N})$, mean, and SD] on endocrine and classical fertility traits in the 14 Swedish Herd Navigator (DeLaval International, Tumba, Sweden) dairy herds studied

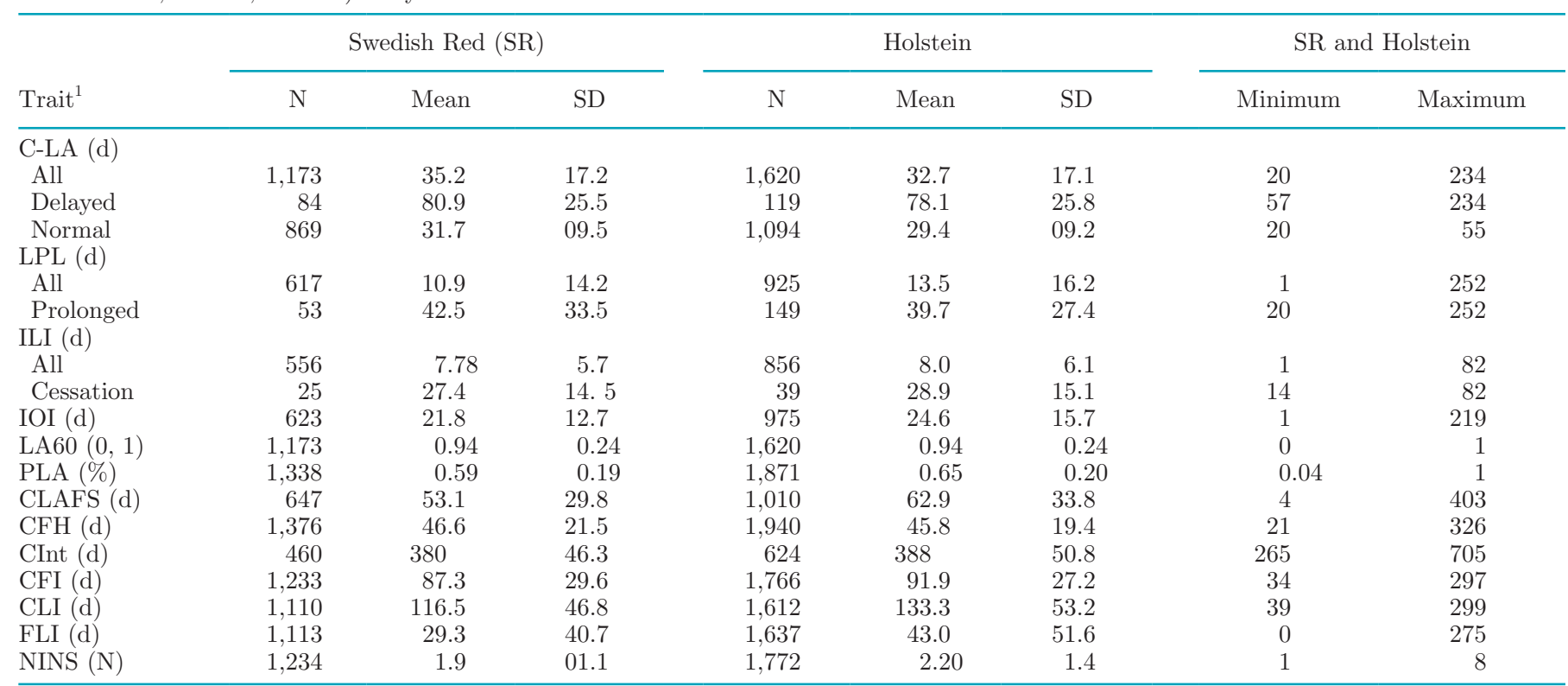

${ }^{1} \mathrm{C}-\mathrm{LA}=$ commencement of luteal activity; normal profile $=$ a first increase in progesterone $(\mathrm{P} 4)$ concentration before $\mathrm{d} 56$ postpartum, followed by 2 wk of high P4 concentration and then 1 wk of low P4 concentration; LPL = first luteal phase length; ILI = length of first inter-luteal interval; IOI $=$ length of first inter-ovulatory interval; LA60 = luteal activity during the first 60 DIM; PLA = proportion of samples with luteal activity; CLAFS = commencement of luteal activity to first service; $\mathrm{CFH}=$ calving to first heat; Delayed $=$ delayed cyclicity $\mathrm{P} 4$ level $<5 \mathrm{ng} / \mathrm{mL}$ for $>56 \mathrm{~d}$ postpartum; Cessation $=$ cessation of cyclicity (cyclicity interrupted for at $\geq 14 \mathrm{~d}$ with P4 level $<5 \mathrm{ng} / \mathrm{mL}$ ); Prolonged $=$ prolonged cyclicity ( $\mathrm{P} 4$ level $>5 \mathrm{ng} / \mathrm{mL}$ for $\geq 20 \mathrm{~d}$ ); CInt = calving interval; CFI = calving to first insemination; CLI = calving to last insemination; FLI $=$ first to last insemination; NINS $=$ number of inseminations per series. 
and LA60 (0.88). In contrast, NINS had weak genetic correlations with all endocrine traits except IOI (0.61). The standard error for most variables was high (range $0.04-0.92)$.

\section{DISCUSSION}

Endocrine fertility traits are suggested as traits of choice to improve fertility in dairy cows. The ability of these traits to explain the actual reproductive status of the cows with little influence of management makes them ideal for use in breeding (Friggens and Chagunda, 2005: Martin et al., 2013). Moreover, the possibility for automated collection and analysis of milk progesterone is now resulting in availability of large quantities of data. In the present study, we evaluated fertility traits of SR and Holstein cows from 14 herds, based on their progesterone records obtained from Herd Navigator inline milk progesterone analysis.

\section{Descriptive Evaluation of Endocrine and Classical Fertility Traits}

The average C-LA was $32.7 \mathrm{~d}$ for Holsteins and 35.2 $\mathrm{d}$ for SR cows (Table 2). Bulman and Lamming (1978) reported that ovulation occurs on average $5 \mathrm{~d}$ before C-LA, which would imply that ovulation occurred approximately on d 28 to 30 postpartum. These results for C-LA are in agreement with previous findings for SR and Holstein cows manually sampled twice weekly until cyclicity, and then once weekly until insemination (C-LA $=34$ d; Petersson et al., 2006b). However, they are smaller than values reported for Dutch HolsteinFriesian herds $(\mathrm{C}-\mathrm{LA}=38.1 \mathrm{~d}$; Tenghe et al., 2015)

Table 3. Least squares means and standard errors (LSM \pm SE) of endocrine and classical fertility traits ${ }^{1}$

\begin{tabular}{|c|c|c|c|c|c|c|c|c|}
\hline \multirow[b]{2}{*}{ Effect } & \multicolumn{2}{|c|}{ C-LA (d) } & \multicolumn{2}{|c|}{ LPL (d) } & \multicolumn{2}{|c|}{ LA60 } & \multicolumn{2}{|c|}{ PLA } \\
\hline & $\mathrm{N}$ & $\mathrm{LSM} \pm \mathrm{SE}$ & $\mathrm{N}$ & $\mathrm{LSM} \pm \mathrm{SE}$ & $\mathrm{N}$ & $\mathrm{LSM} \pm \mathrm{SE}$ & $\mathrm{N}$ & $\mathrm{LSM} \pm \mathrm{SE}$ \\
\hline Breed & & $* *$ & & ** & & NS & & $* *$ \\
\hline Swedish Red & 1,173 & $36.2 \pm 0.56^{\mathrm{a}}$ & 631 & $11.3 \pm 0.57^{\mathrm{b}}$ & 1,173 & $0.93 \pm 0.01$ & 1,338 & $0.58 \pm 0.00^{\mathrm{b}}$ \\
\hline Holstein & 1,620 & $33.7 \pm 0.49^{\mathrm{b}}$ & 945 & $14.1 \pm 0.57^{\mathrm{a}}$ & 1,620 & $0.93 \pm 0.00$ & 1,871 & $0.65 \pm 0.01^{\mathrm{a}}$ \\
\hline Parity & & $* * *$ & & $*$ & & NS & & $*$ \\
\hline 1 & 1,075 & $32.7 \pm 0.52^{\mathrm{c}}$ & 512 & $10.2 \pm 0.69^{\mathrm{b}}$ & 1,075 & $0.94 \pm 0.01$ & 1,226 & $0.63 \pm 0.01^{\mathrm{a}}$ \\
\hline 2 & 824 & $33.9 \pm 0.59^{\mathrm{bc}}$ & 456 & $12.6 \pm 0.73^{\mathrm{a}}$ & 824 & $0.94 \pm 0.01$ & 956 & $0.61 \pm 0.01^{\mathrm{b}}$ \\
\hline 3 & 472 & $34.1 \pm 0.78^{\mathrm{bc}}$ & 336 & $13.3 \pm 0.84^{\mathrm{a}}$ & 472 & $0.95 \pm 0.01$ & 553 & $0.61 \pm 0.02^{\mathrm{ab}}$ \\
\hline 4 & 273 & $37.1 \pm 1.0^{\mathrm{a}}$ & 177 & $14.0 \pm 1.2^{\mathrm{a}}$ & 273 & $0.91 \pm 0.01$ & 301 & $0.62 \pm 0.01^{\mathrm{ab}}$ \\
\hline 5 & 149 & $36.8 \pm 1.3^{\mathrm{ab}}$ & 95 & $13.3 \pm 1.6^{\mathrm{a}}$ & 149 & $0.92 \pm 0.02$ & 173 & $0.59 \pm 0.01^{\mathrm{b}}$ \\
\hline Season $^{2}$ & & $* * *$ & & NS & & $* * *$ & & $* *$ \\
\hline Winter & 782 & $35.4 \pm 0.66^{\mathrm{ab}}$ & 419 & $12.90 \pm 0.79$ & 782 & $0.93 \pm 0.00^{\mathrm{b}}$ & 888 & $0.61 \pm 0.01^{\mathrm{b}}$ \\
\hline Spring & 677 & $37.8 \pm 0.70^{\mathrm{a}}$ & 374 & $13.77 \pm 0.84$ & 677 & $0.90 \pm 0.00^{\mathrm{b}}$ & 692 & $0.60 \pm 0.01^{\mathrm{b}}$ \\
\hline Summer & 658 & $32.9 \pm 0.71^{\mathrm{cb}}$ & 432 & $12.22 \pm 0.80$ & 658 & $0.96 \pm 0.01^{\mathrm{a}}$ & 752 & $0.64 \pm 0.01^{\mathrm{a}}$ \\
\hline \multirow[t]{3}{*}{ Autumn } & 676 & $33.6 \pm 0.71^{\mathrm{b}}$ & 351 & $11.87 \pm 0.88$ & 676 & $0.94 \pm 0.01^{\mathrm{ab}}$ & 877 & $0.61 \pm 0.01^{\mathrm{b}}$ \\
\hline & \multicolumn{2}{|r|}{ ILI (d) } & \multicolumn{2}{|c|}{ IOI (d) } & \multicolumn{2}{|c|}{ NINS (n) } & \multicolumn{2}{|c|}{ CInt (d) } \\
\hline & $\mathrm{N}$ & $\mathrm{LSM} \pm \mathrm{SE}$ & $\mathrm{N}$ & $\mathrm{LSM} \pm \mathrm{SE}$ & $\mathrm{N}$ & $\mathrm{LSM} \pm \mathrm{SE}$ & $\mathrm{N}$ & $\mathrm{LSM} \pm \mathrm{SE}$ \\
\hline Breed & & NS & & $* * *$ & & $* * *$ & & $* *$ \\
\hline Swedish Red & 660 & $7.98 \pm 0.28$ & 623 & $22.3 \pm 0.65$ & 1,234 & $1.90 \pm 0.04^{\mathrm{b}}$ & 460 & $382 \pm 2.8^{\mathrm{b}}$ \\
\hline Holstein & 1,003 & $8.34 \pm 0.23$ & 974 & $25.2 \pm 0.53$ & 1,772 & $2.20 \pm 0.04^{\mathrm{a}}$ & 624 & $390 \pm 2.5^{\mathrm{a}}$ \\
\hline Parity & & $* * *$ & & $* * *$ & & NS & & $* *$ \\
\hline 1 & 457 & $6.67 \pm 0.28^{\mathrm{b}}$ & 536 & $20.8 \pm 0.64^{\mathrm{b}}$ & 1,184 & $2.00 \pm 0.04$ & 496 & $378 \pm 2.2^{\mathrm{b}}$ \\
\hline 2 & 429 & $8.19 \pm 0.29^{\mathrm{a}}$ & 467 & $24.2 \pm 0.68^{\mathrm{a}}$ & 908 & $2.10 \pm 0.04$ & 305 & $385 \pm 2.8^{\mathrm{a}}$ \\
\hline 3 & 296 & $8.58 \pm 0.34^{\mathrm{a}}$ & 335 & $24.0 \pm 0.80^{\mathrm{a}}$ & 524 & $2.04 \pm 0.06$ & 161 & $389 \pm 3.8^{\mathrm{a}}$ \\
\hline 4 & 151 & $9.20 \pm 0.48^{\mathrm{a}}$ & 166 & $26.1 \pm 1.1^{\mathrm{a}}$ & 258 & $2.08 \pm 0.08$ & 82 & $390 \pm 5.4^{\mathrm{a}}$ \\
\hline 5 & 79 & $8.57 \pm 0.67^{\mathrm{a}}$ & 93 & $23.6 \pm 1.5^{\mathrm{ab}}$ & 132 & $2.03 \pm 0.11$ & 40 & $389 \pm 7.7^{\mathrm{a}}$ \\
\hline Season $^{2}$ & & NS & & NS & & $* * *$ & & $* *$ \\
\hline Winter & 439 & $8.23 \pm 0.32$ & 425 & $24.1 \pm 0.76$ & 832 & $1.99 \pm 0.05^{\mathrm{b}}$ & 304 & $394 \pm 3.1^{\mathrm{a}}$ \\
\hline Spring & 409 & $8.61 \pm 0.34$ & 390 & $24.3 \pm 0.78$ & 662 & $1.95 \pm 0.05^{\mathrm{b}}$ & 234 & $393 \pm 3.6^{\mathrm{a}}$ \\
\hline Summer & 451 & $7.85 \pm 0.33$ & 424 & $22.8 \pm 0.76$ & 686 & $2.05 \pm 0.05^{\mathrm{b}}$ & 213 & $371 \pm 3.7^{\mathrm{c}}$ \\
\hline Autumn & 364 & $7.94 \pm 0.35$ & 358 & $23.9 \pm 0.82$ & 826 & $2.22 \pm 0.05^{\mathrm{a}}$ & 333 & $386 \pm 3.1^{b}$ \\
\hline
\end{tabular}

${ }^{a-c}$ LSM with different superscript letters differ significantly.

${ }^{1} \mathrm{C}-\mathrm{LA}=$ commencement of luteal activity; LPL $=$ first luteal phase length; LA60 = luteal activity during the first 60 DIM; PLA $=$ proportion of samples with luteal activity; ILI = length of first inter-luteal interval; IOI $=$ length of first inter-ovulatory interval; NINS $=$ number of inseminations per series; CInt $=$ calving interval; $\mathrm{N}=$ number of observations.

${ }^{2}$ Season $=$ calving season; spring $=$ March-May; summer = June-August; autumn = September-November; winter $=$ December-February .

$* P<0.05 ; * * P<0.01 ; * * P<0.001$ 
Table 4. Estimates of heritability $\left(h^{2}\right)$, standard error (SE), and additive genetic variance $\left(\sigma_{a}^{2}\right.$; log-transformed scale) obtained for endocrine and classical fertility traits in Holstein and Swedish Red (SR) dairy cows

\begin{tabular}{|c|c|c|c|c|c|c|c|c|c|}
\hline Trait $^{1}$ & \multicolumn{3}{|c|}{ Holstein and SR } & \multicolumn{3}{|c|}{ Holstein } & \multicolumn{3}{|c|}{$\mathrm{SR}$} \\
\hline LPL & 0.08 & 0.04 & 0.01 & 0.12 & 0.06 & 0.03 & 0.00 & 0.06 & 0.00 \\
\hline ILI & 0.00 & 0.03 & 0.00 & 0.00 & 0.04 & 0.00 & 0.00 & 0.06 & 0.00 \\
\hline IOI & 0.03 & 0.04 & 0.002 & 0.09 & 0.06 & 0.005 & 0.00 & 0.06 & 0.00 \\
\hline LA60 & 0.15 & 0.04 & 0.01 & 0.14 & 0.04 & 0.01 & 0.20 & 0.06 & 0.01 \\
\hline $\mathrm{CFH}$ & 0.18 & 0.05 & 0.004 & 0.20 & 0.04 & 0.005 & 0.14 & 0.05 & 0.003 \\
\hline CFI & 0.03 & 0.001 & 0.00 & 0.04 & 0.00 & 0.00 & 0.00 & 0.00 & 0.00 \\
\hline CLI & 0.06 & 0.001 & 0.002 & 0.07 & 0.00 & 0.002 & 0.00 & 0.03 & 0.00 \\
\hline FLI & 0.04 & 0.02 & 0.03 & 0.00 & 0.05 & 0.00 & 0.02 & 0.03 & 0.01 \\
\hline NINS & 0.02 & 0.06 & 0.08 & 0.06 & 0.03 & 0.10 & 0.04 & 0.04 & 0.05 \\
\hline CInt & 0.15 & 0.08 & 0.00 & 0.16 & 0.12 & 0.00 & 0.00 & 0.09 & 0.00 \\
\hline
\end{tabular}

C-LA = commencement of luteal activity (all C-LA profiles); LPL = first luteal phase length (all LPL profiles); ILI $=$ length of first inter-luteal interval (all ILI profiles); IOI $=$ length of first inter-ovulatory interval; LA60 = luteal activity during the first 60 DIM; PLA = proportion of samples with luteal activity; CLAFS = commencement of luteal activity to first service; CFH $=$ calving to first heat; CFI $=$ calving to first insemination in days; CLI = calving to last insemination in days; FLI $=$ first to last insemination in days; NINS $=$ number of inseminations per series; CInt $=$ calving interval in days

and for Nordic Red cows in Finland (C-LA = 39.8, 37.7, and $40.6 \mathrm{~d}$ for parities 1,2 and 3, respectively; Häggman et al., 2019). However, our C-LA estimate for Holsteins is $2.5 \mathrm{~d}$ longer than the overall mean reported for 4 Holstein-Friesian experimental herds in Sweden, the Netherlands, the UK, and Ireland (C-LA $=31.1$; Nyman et al., 2014). The latter value was based on manual sampling twice weekly in Sweden and the Netherlands and thrice weekly in Ireland and the UK. The average C-LA for SR in the present study was 2 to $5 \mathrm{~d}$ shorter than that reported for Nordic Red cows in Finland, despite the fact that this breed is closely related to SR in Sweden. Differences in data recording and editing between the studies may explain the difference. These reasons may also explain the difference in C-LA observed between Holsteins in the Dutch and Swedish dairy herds. The selection pressure put on milk yield may vary between countries, which could influence C-LA (Lopez et al., 2004; Nyman et al., 2014; Häggman et al., 2019). The filtering criteria used in the present study could also have contributed to the observed differences. For instance, when defining C-LA, we used a 5-d-earlier limit (at 20 DIM) than used in Tenghe et al. (2015).

The intervals observed for all endocrine and classical traits (except C-LA, CFH, and atypical profiles) were longer for Holstein cows than for SR cows (Table 2). For instance, SR cows had an estimated 21-d cycle of IOI and an IOI up to $4.4 \mathrm{~d}$ shorter than Holsteins or Holstein-Friesians in the Netherlands (Tenghe et al., 2015) and the aggregated data set of Holstein-Friesian herds from 4 countries studied in Nyman et al. (2014). Similarly, both breeds in the present study had shorter C-LA, LPL, and ILI than Dutch Holstein-Friesians

Table 5. Estimates of genetic correlations with endocrine and classical fertility traits (above diagonal) and standard errors (below diagonal)

\begin{tabular}{lcccrrrrr}
\hline Trait $^{1}$ & C-LA & LPL & IOI & CLAFS & LA60 & PLA & CFH & NINS \\
\hline C-LA & & 0.08 & 0.29 & -0.53 & -0.88 & -0.72 & 0.90 & 0.21 \\
LPL & 0.27 & & NC $^{2}$ & 0.29 & -0.04 & 0.54 & 0.49 & 0.19 \\
IOI & 0.39 & NC & & 0.01 & 0.16 & 0.42 & 0.98 & 0.61 \\
CLAFS & 0.35 & 0.40 & 0.58 & & 0.25 & 0.99 & -0.20 & 0.11 \\
LA60 & 0.06 & 0.42 & 0.39 & 0.63 & & 0.39 & 0.88 & 0.17 \\
PLA & 0.11 & 0.30 & 0.25 & 0.37 & 0.17 & & -0.31 & -0.11 \\
CFH & 0.04 & 0.20 & 0.20 & 0.35 & 0.04 & 0.14 & & 0.40 \\
NINS & 0.25 & 0.92 & 0.46 & 0.19 & 0.29 & 0.24 & 0.23 &
\end{tabular}

${ }^{1} \mathrm{C}-\mathrm{LA}=$ commencement of luteal activity (all C-LA profiles); LPL = first luteal phase length (all LPL profiles); IOI = length of first inter-ovulatory interval; LA60 = luteal activity during the first 60 DIM; PLA = proportion of samples with luteal activity; CLAFS = commencement of luteal activity to first service; $\mathrm{CFH}=$ calving to first heat; NINS = number of inseminations per series.

${ }^{2} \mathrm{NC}=$ not converged. 
(Tenghe et al., 2015). A similar trend was observed for classical traits. However, although endocrine fertility traits were similar, classical traits of SR cows in the present study had slightly higher CFI, CLI, and FLI compared with the Nordic Red cows studied by Häggman et al. (2019). Variations in herd management and in data editing could have contributed to these differences. The first heat was observed, on average, $11.4 \mathrm{~d}$ after C-LA for SR, which is $2.85 \mathrm{~d}$ longer than reported for Nordic Red cows in Finland (Häggman et al., 2019). The incidence of short (29.3\%), normal (40.7\%), and long $(30.0 \%)$ IOI determined in the present study was similar to that reported for Holstein-Friesian herds in Sweden, the Netherlands, the UK, and Ireland (Nyman et al., 2014).

To obtain a 1-yr calving interval, cow cyclicity should resume within $60 \mathrm{~d}$ postpartum (Walsh et al., 2011). This is why PLA was considered an important trait, indicating the start of luteal activity and also a cow's cyclicity after ovulation (Petersson et al., 2006a; Tenghe et al., 2015). We obtained a PLA of 0.63 for the combined data set, 0.59 for SR, and 0.65 for Holstein. These values are higher than those reported for Swedish, UK, and Dutch Holstein-Friesian herds (Petersson et al., 2007; Tenghe et al., 2015). This could be due to differences in the number of samples taken in a fixed period and persistence of the corpus luteum, which would inflate PLA values.

We detected differences between the breeds and across parities for C-LA, LPL, IOI, and PLA. Holstein had 2.5 $\mathrm{d}$ earlier C-LA and longer LPL and IOI than SR. The highest mean intervals for C-LA, LPL, and IOI were observed in fourth parity and the lowest in first parity. These results are in agreement with the study by Blavy et al. (2016), who found longer LPL for Holstein than for Danish Red and longer LPL by parity number. Cows calving in spring had 4.9-d-longer luteal activity than those calving in summer. In contrast, cows calving in summer (longer daylight than darkness) had LA60 6 percentage units higher than spring calvers. It has been found that photoperiod or temperature can affect luteal activity more strongly than diet or management in SR and Holstein cows (Petersson et al., 2006a).

In general, low values for C-LA, CFH, CLAFS, CInt, CFI, CLI, FLI, and NINS and high values of PLA and LA60 are indicators of better fertility. Values of LPL, ILI, and IOI that are too long indicate fertility problems, but there is an optimal lower limit of these intervals. A shorter C-LA $(\mathrm{CFH})$ gives the farmer an opportunity to start to inseminate early and thus achieve a short calving interval. A short CLAFS indicates that the cow tended to show heat and was inseminated soon after first luteal activity.

\section{Estimates of Heritability and Genetic Correlation}

The genetic analysis produced higher heritability estimates for endocrine fertility traits (e.g., $h^{2}=0.26$, maximum heritability value of C-LA for SR cows) than for the classical fertility traits (Table 4), indicating a comparative advantage of some endocrine fertility traits over classical traits for fertility evaluation in dairy cows. The low heritability estimates for the classical fertility traits could be attributed to a multitude of factors, including, for example, that the traits are truly under poor additive genetic control relative to nonadditive and nongenetic factors (Berry et al., 2012). It is also claimed that low heritability estimates together with an unfavorable relationship between production and fertility traits complicates genetic improvement (Nyman et al., 2019). Daetwyler et al. (2008) pointed out that the level of heritability for a trait influences the success of genome-wide association studies. Thus, the use of more heritable hormonal profiles related to fertility performance should help increase genetic improvement (Berry et al., 2012). The heritability estimates obtained for endocrine traits of SR and Holstein cows in the current study were higher than those reported for HolsteinFriesian herds in Ireland, the UK, the Netherlands, and Sweden (e.g., C-LA: $h^{2}=0.13$; Berry et al., 2012) and for Holstein-Friesian herds in the Netherlands based on in-line milk P4 information using Herd Navigator $\left(h^{2}=0.14\right.$; Tenghe et al., 2015). However, the values were similar to that reported for Nordic Red cows in Finland $\left(h^{2}=0.24\right.$, using univariate model; Häggman et al., 2019). Nyman et al. (2014) reported heritability estimates of $0.18,0.08,0.08$, and 0.03 for C-LA, ILI, LPL, and IOI, respectively, for Swedish, Dutch, UK, and Irish Holstein-Friesian herds using manually collected progesterone information.

Our heritability estimates for PLA (0.12 for Holstein and 0.14 for SR) are in agreement with that (0.12) reported for Dutch Holstein-Friesian herds (Tenghe et al., 2015). Petersson et al. (2007) found lower estimates of heritability for PLA with more infrequent sampling $(0.25,0.20$, and 0.14 for weekly, twice-monthly, and monthly sampling, respectively). Moderate heritability (0.16) for CInt was obtained for Holstein cows in the present study, but zero heritability for SR cows. The former was higher than the heritability of other classical traits in our study and compared with previous findings for Dutch herds (0.05; Tenghe et al., 2015). However, it is important to note that we obtained zero heritability for several endocrine and classical fertility traits in SR cows. Similar findings were made in the study in Finland on Nordic Red cows (except for C-LA and $\mathrm{CFH}$ ); therefore, these variables were excluded 
from their paper (Jarmo Juga, University of Helsinki, Helsinki, Finland, personal communication, 2018). This suggests that further studies are necessary on larger groups of Red cows in the Nordic countries to obtain reliable genetic parameter estimates for this breed. Length of first ILI consistently showed zero heritability estimates for SR, Holstein, and both breeds combined, suggesting that this may not be a useful endocrine trait to include in the breeding goal. Most of the correlation estimates had high standard errors, because of the small sample size (Berry et al., 2012). The strong correlations of C-LA with LA60 (-0.88), PLA $(-0.72)$, and CFH (0.90) suggest that these traits reflect almost the same parameter. Similar strong correlations for C-LA with LA60, PLA, and CFH have been reported by Nyman et al. (2014), Tenghe et al. (2015), and Häggman et al. (2019). In contrast to our findings, Berry et al. (2012) obtained a very weak correlation (0.29) between C-LA and CFH. Consistent with Nyman et al. (2014), IOI had a strong correlation with $\mathrm{CFH}(0.88)$ in the present study. Petersson et al. (2007) suggest that PLA has an intermediate optimum value: too high a value for PLA is unfavorable, because it is associated with persistence of corpus luteum type 1 , but too low a value could also be unfavorable, because it is associated with delayed ovulation type 1 .

Overall, we believe that endocrine traits have the potential to better reflect the biological fertility status of the dairy cows than classical traits do. Therefore, they should be considered as part of the selection criteria and the breeding goal. A prerequisite is that automated progesterone scoring or recording resources are made available for routine recording as part of national databases.

\section{CONCLUSIONS}

Most of the endocrine traits studied, including C-LA, LA60, PLA, and CFH, were found to be moderately heritable and strongly correlated with each other. Classical traits had lower heritability estimates and weak genetic correlations with endocrine traits. Our results confirm previous findings that endocrine traits might have the potential to better describe the actual reproductive status of dairy cows than classical traits, and suggests that some endocrine fertility traits, especially those related to commencement of luteal activity, may increase the rate of genetic improvement if used as additional selection criteria and in the breeding goal. Swedish Red cows appeared superior to Holstein in some fertility traits, but showed zero heritability for LPL, IOI, CLAFS, and CFH, which warrants further studies on a larger sample of Red cattle. It is important that endocrine progesterone data from automatic devices be made available to recording and breeding organizations in the future and included in a central database.

\section{ACKNOWLEDGMENTS}

We acknowledge the herd owners in Sweden who contributed data on their herds. This study was performed within the Swedish part of the Nordic research project NorFert (Improving Nordic dairy cow fertility through genetics). The main participant is the Swedish University of Agricultural Sciences (SLU). Industry partners are Växa Sverige (Stockholm, Sweden), VikingGenetics (Randers, Denmark), Nordic Cattle Genetic Evaluation Ltd. (NAV, Aarhus, Denmark), and Lattec I/S (Hillerod, Denmark). NorFert project partners are the Natural Resource Institute of Finland (Luke, Jokioinen, Finland) and Helsinki University, Helsinki, Finland, Aarhus University, Aarhus, Denmark, and NMBU, Aas, Norway. We are grateful for the funding for the project provided by the Swedish Farmers' Foundation for Agricultural Research (Project ID: O-15-20-587). The authors declare no conflicts of interest.

\section{REFERENCES}

Adriaens, I., T. Huybrechts, K. Geerinckx, D. Daems, J. Lammertyn, B. De Ketelaere, W. Saeys, and B. Aernouts. 2017. Mathematical characterization of the milk progesterone profile as a leg up to individualised monitoring of reproduction status in dairy cows. Theriogenology 103:44-51.

Adriaens, I., W. Saeys, T. Huybrechts, C. Lamberigts, L. François, K. Geerinckx, J. Leroy, B. D. Ketelaere, and B. Aernouts. 2018. A novel system for on-farm fertility monitoring based on milk progesterone. J. Dairy Sci. 101:8369-8382.

Berry, D. P., J. W. M. Bastiaansen, R. F. Veerkamp, S. Wijga, E. Wall, B. Berglund, and M. P. L. Calus. 2012. Genome-wide associations for fertility traits in Holstein-Friesian dairy cows using data from experimental research herds in four European countries. Animal 6:1206-1215.

Blavy, P., M. Derks, O. Martin, J. K. Höglund, and N. C. Friggens. 2016. Overview of progesterone profiles in dairy cows. Theriogenology 86:1061-1071.

Bruinjé, T. C., M. G. Colazo, E. S. Ribeiro, M. D. Gobikrushanth, and J. Ambrose. 2019. Using in-line milk progesterone data to characterize parameters of luteal activity and their association with fertility in Holstein cows. J. Dairy Sci. 102:780-798.

Bulman, D. C., and G. E. Lamming. 1978. Milk progesterone levels in relation to conception, repeat breeding and factors influencing acyclicity in dairy cows. J. Reprod. Fertil. 54:447-458.

Daetwyler, H. D., B. Villanueva, and J. A. Woolliams. 2008. Accuracy of predicting the genetic risk of disease using a genome-wide approach. PLoS One 3:e3395.

DeLaval International. 2011. Herd Navigator and reproduction management. Accessed Feb. 4, 2019. http://delaval-com-www .gtm.episerverhosting.com/PageFiles/171203/53571175_HN _Reproduktion managementLOWRES.pdf.

Edwards, S. M. 2017. Standard errors of heritability estimates. Accessed Feb. 11, 2019. http://www.iysik.com/dmu/heritabilities.

Friggens, N. C., and M. G. G. Chagunda. 2005. Prediction of the reproductive status of cattle on the basis of milk progesterone measures: Model description. Theriogenology 64:155-190. 
Häggman, J., J. M. Christensen, E. A. Mäntysaari, and J. Juga. 2019. Genetic parameters for endocrine and traditional fertility traits, hyperketonemia and milk yield in dairy cattle. Animal 13:248-255.

Leroy, J. L. M. R., G. Opsomer, A. Van Soom, I. G. F. Goovaerts, and P. E. J. Bols. 2008. Reduced fertility in high-yielding dairy cows: are the oocyte and embryo in danger? Part I. The importance of negative energy balance and altered corpus luteum function to the reduction of oocyte and embryo quality in high-yielding dairy cows. Reprod. Domest. Anim. 43:612-622.

Lopez, H., L. D. Satter, and M. C. Wiltbank. 2004. Relationship between level of milk production and estrous behavior of lactating dairy cows. Anim. Reprod. Sci. 81:209-223.

Madsen, P., and J. Jensen. 2013. A user's guide to DMU. A package for analyzing multivariate mixed models. Version 6 , release 5.2. Department of Genetics and Biotechnology, Faculty of Life Sciences, University of Aarhus, Research Centre Foulum, Tjele, Denmark.

Martin, O., N. C. Friggens, J. Dupont, P. Salvetti, S. Freret, C. Rame, S. Elis, J. Gatien, C. Disenhaus, and F. Blanc. 2013. Data-derived reference profiles with core presentation of progesterone, estradiol, LH, and FSH dynamics during the bovine estrous cycle. Theriogenology 79:331-343.

Nyman, S., S. I. Duchemin, D. J. de Koning, and B. Berglund. 2019. Genome-wide association study of normal and atypical progesterone profiles in Holstein-Friesian dairy cows. J. Dairy Sci. 102:32043215.

Nyman, S., K. Johansson, D. J. de Koning, D. P. Berry, R. F. Veerkamp, E. Wall, and B. Berglund. 2014. Genetic analysis of atypical progesterone profiles in Holstein-Friesian cows from experimental research herds. J. Dairy Sci. 97:7230-7239.

Petersson, K. J., B. Berglund, E. Strandberg, H. Gustafsson, A. P. F Flint, J. A. Woolliams, and M. D. Royal. 2007. Genetic analysis of postpartum measures of luteal activity in dairy cows. J. Dairy Sci. 90:427-434.

Petersson, K. J., H. Gustafsson, E. Strandberg, and B. Berglund. 2006a. Atypical progesterone profiles and fertility in Swedish dairy cows. J. Dairy Sci. 89:2529-2538.
Petersson, K. J., E. Strandberg, H. Gustafsson, and B. Berglund. 2006b. Environmental effects on progesterone profile measures of dairy cow fertility. Anim. Reprod. Sci. 91:201-214.

Royal, M. D., A. O. Darwash, A. P. F. Flint, R. Webb, J. A. Woolliams, and G. E. Lamming. 2000a. Declining fertility in dairy cattle: Changes in traditional and endocrine parameters of fertility. Anim. Sci. 70:487-501.

Royal, M., G. E. Mann, and A. P. F. Flint. 2000b. Strategies for reversing the trend towards subfertility in dairy cattle. Vet. J. 160:53-60.

Saint-Dizier, M., and S. Chastant-Maillard. 2012. Towards an automated detection of oestrus in dairy cattle. Reprod. Domest. Anim. 47:1056-1061.

SAS Institute. 2012. SAS/STAT ${ }^{\circledR} 12.1$ User's Guide. SAS Institute Inc., Cary, NC.

Tenghe, A. M., A. C. Bouwman, B. Berglund, E. Strandberg, J. Y. Blom, and R. F. Veerkamp. 2015. Estimating genetic parameters for fertility in dairy cows from in-line milk progesterone profiles. J. Dairy Sci. 98:5763-5773.

Walsh, S. W., E. J. Williams, and A. C. O. Evans. 2011. A review of the causes of poor fertility in high milk producing dairy cows. Anim. Reprod. Sci. 123:127-138.

\section{ORCIDS}

G. M. Tarekegn ๑ https://orcid.org/0000-0001-7221-2473

P. Gullstrand (1) https://orcid.org/0000-0002-7450-8208

E. Strandberg () https://orcid.org/0000-0001-5154-8146

R. Båge () https://orcid.org/0000-0003-1413-6913

J. M. Christensen (® https://orcid.org/0000-0002-6503-5066 